\title{
Erythropoietin for Optic Neuritis
}

\author{
Rod Foroozan, MD \\ Division of Neuro-Ophthalmology, Baylor College of Medicine, Houston, TX, USA \\ ORCID: \\ Rod Foroozan: https://orcid.org/0000-0002-7937-830X
}

J Ophthalmic Vis Res 2019; 14 (3): 240-242

Inflammatory optic neuropathy remains the most common acute optic neuropathy in patients under the age of 50 years. The most common cause for inflammatory optic neuropathy is sterile inflammation from demyelination, with multiple sclerosis (MS) as the most common associated condition. This is the type of optic neuropathy most commonly referred to as "optic neuritis." The inflammation more commonly occurs posteriorly, does not cause optic disc edema, and is termed retrobulbar optic neuritis.

For the last 25 years or so, and primarily based on information from the optic neuritis treatment trial (ONTT), ${ }^{[1]}$ the standard treatment for acute inflammatory optic neuritis has been high dose corticosteroids, typically given intravenously for 35 days, followed by oral steroids. The expectation is that corticosteroids will hasten visual improvement without altering the degree of recovery of visual function. There has been a relative paucity of adjunctive agents that have been used in conjunction with corticosteroids. Given the persistent deficits that remain after a bout of optic neuritis, there remains an unmet need for neuroprotective therapy.

Erythropoietin, best recognized as a regulator of erythropoiesis, has shown potential neuroprotective properties in animal models of brain injury, including that from ischemia, trauma, ${ }^{[2,3]}$ epilepsy, and optic neuropathy. ${ }^{[4,5]}$ A rat model using immunization with myelin oligodendrocyte glycoprotein (MOG) showed functional and histopathological improvement of retinal ganglion cells and optic nerves when erythropoietin treatment was combined with high dose methylprednisolone therapy. ${ }^{[6]}$

The use of erythropoietin in humans with optic neuropathy has been reported in multiple studies from Iran. The treated conditions included traumatic optic neuropathy, ${ }^{[7,8]}$ nonarteritic anterior ischemic optic neuropathy, ${ }^{[9,10]}$ multiple sclerosis, ${ }^{[11]}$ and methanol optic neuropathy. ${ }^{[12-14]}$ With some exceptions (particularly methanol optic neuropathy), the proof of benefit has been rather underwhelming thus far; however, the balance of evidence suggests that there has been no harm to visual function (although one patient was reported to develop cerebral venous sinus thrombosis ${ }^{[11]}$ ).

One confounding issue with prior studies assessing the effect of erythropoietin on optic neuropathy is that the method of administration of the agent varied and included intravenous injection, intravitreal injection, and the use of microspheres. In addition, the dose of erythropoietin was inconsistent between the studies.

In this issue, Soltan Sanjari and coworkers assessed the addition of intravenous recombinant human erythropoietin (IVE) to intravenous methylprednisolone (IVMP) in patients with retrobulbar optic neuritis. Thirty-five patients were treated with IVMP alone and twenty-seven with the combination of IVMP and IVE (20,000 international units). Both groups were treated with intravenous agents for 3 days and were then given 11 days of oral prednisolone at $1 \mathrm{mg} / \mathrm{kg}$. The primary outcome measure was the change in best corrected visual acuity, which was assessed up to 120 days. Other measures of visual function included contrast sensitivity (Yang vision tester), color vision (Ishihara pseudoisochromatic color plates), and automated perimetry (Humphrey 24-2 SITA Standard). ${ }^{[15]}$

While the cited inclusion criteria were described as those from the ONTT, it was not clear what ancillary laboratory studies were performed, and specifically whether blood was sent for aquaporin4 and anti-MOG antibodies. ${ }^{[15]}$

By three months, there was no difference in the visual acuity between the two groups. In 
addition, there was no suggestion that the rate of visual recovery was different between the two groups. The mean deviation on automated perimetry showed no difference between the two groups at three months. There was also no difference in the contrast sensitivity and color vision between the two groups after treatment. ${ }^{[15]}$

The authors should be commended for enrolling a relatively large number of patients with inflammatory optic neuropathy within a short (10 day) window of symptoms. It was slightly disappointing that there were no structural, objective measures such as optical coherence tomography (OCT) of the retinal nerve fiber layer (RNFL), ganglion cell layer, or macula, particularly given the citation of work from another group which showed less RNFL thinning in patients with optic neuritis treated with IVE (33,000 international units) and IVMP for three days. ${ }^{[16]}$

While this was a negative study in terms of primary visual outcome, the authors point out that there was no evidence of clinically relevant side effects of IVE treatment. This is consistent with the prior literature. Regardless of the route of administration (including intravitreal injection), the use of erythropoietin appears to be safe, which is encouraging given the approval of a randomized, placebo-controlled trial [clinicaltrials.gov (NCT01962571)] from a group of investigators in Germany. ${ }^{[17]}$

So far, IVE for optic neuritis and demyelination ${ }^{[18]}$ has not proven to be a game changer. If additional studies are performed, I would encourage the authors to include additional measures of structure and function of the visual pathways to ensure that the focus is not solely on central visual function.

\section{REFERENCES}

1. Beck RW, Cleary PA, Anderson MM, Jr., Keltner JL, Shults WT, Kaufman DI, et al. A randomized, controlled trial of corticosteroids in the treatment of acute optic neuritis. The Optic Neuritis Study Group. N Engl J Med 1992;326:581588.

2. King CE, Rodger J, Bartlett C, Esmaili T, Dunlop SA, Beazley LD. Erythropoietin is both neuroprotective and neuroregenerative following optic nerve transection. Exp Neurol 2007;205:48-55.

3. Tan $\mathrm{H}$, Zhong $\mathrm{Y}$, Shen $\mathrm{X}$, Cheng $\mathrm{Y}$, Jiao $\mathrm{Q}$, Deng $\mathrm{L}$. Erythropoietin promotes axonal regeneration after optic nerve crush in vivo by inhibition of RhoA/ROCK signaling pathway. Neuropharmacology 2012;63:1182-1190.
4. Weishaupt JH, Rohde G, Polking E, Siren AL, Ehrenreich H, Bahr M. Effect of erythropoietin axotomy-induced apoptosis in rat retinal ganglion cells. Invest Ophthalmol Vis Sci 2004;45:1514-1522.

5. Zhong L, Bradley J, Schubert W, Ahmed E, Adamis AP, Shima DT, et al. Erythropoietin promotes survival of retinal ganglion cells in DBA/2J glaucoma mice. Invest Ophthalmol Vis Sci 2007;48:1212-1218.

6. Diem R, Sattler MB, Merkler D, Demmer I, Maier K, Stadelmann $\mathrm{C}$, et al. Combined therapy with methylprednisolone and erythropoietin in a model of multiple sclerosis. Brain 2005;128:375-385.

7. Kashkouli MB, Pakdel F, Sanjari MS, Haghighi A, Nojomi $\mathrm{M}$, Homaee $\mathrm{MH}$, et al. Erythropoietin: a novel treatment for traumatic optic neuropathy-a pilot study. Graefes Arch Clin Exp Ophthalmol 2011;249:731-736.

8. Entezari M, Esmaeili M, Yaseri M. A pilot study of the effect of intravenous erythropoetin on improvement of visual function in patients with recent indirect traumatic optic neuropathy. Graefes Arch Clin Exp Ophthalmol 2014;252:1309-1313.

9. Modarres M, Falavarjani KG, Nazari $H$, Soltan Sanjari M, Aghamohammadi F, Homaii M, et al. Intravitreal erythropoietin injection for the treatment of non-arteritic anterior ischaemic optic neuropathy. $\mathrm{Br} J$ Ophthalmol 2011;95:992-995.

10. Pakravan M, Esfandiari H, Hassanpour K, Razavi S, Pakravan P. The effect of combined systemic erythropoietin and steroid on non-arteritic anterior ischemic optic neuropathy: a prospective study. Curr Eye Res 2017;42:1079-1084.

11. Borhani-Haghighi A, Ghodsi M, Razeghinejad MR, Mardani S, Mardani M, Nikseresht AR, et al. Erythropoietin for acute multiple sclerosis in patients with optic neuritis as a first demyelination event. Neurosciences (Riyadh) 2012;17:151155.

12. Pakravan M, Sanjari N. Erythropoietin treatment for methanol optic neuropathy. J Neuroophthalmol 2012;32: 325-328.

13. Pakravan M, Esfandiari H, Sanjari N, Ghahari E. Erythropoietin as an adjunctive treatment for methanol-induced toxic optic neuropathy. Am J Drug Alcohol Abuse 2016;42:633639.

14. Pakdel F, Sanjari MS, Naderi A, Pirmarzdashti N, Haghighi A, Kashkouli MB. Erythropoietin in treatment of methanol optic neuropathy. J Neuroophthalmol 2018;38:167-171.

15. Soltan Sanjari M, Pakdel F, Moosavi F, Pirmarzdashti N, Nojomi M, Haghighi A, et al. Visual outcomes of adding erythropoietin to methylprednisolone for treatment of retrobulbar optic neuritis. J Ophthalmic Vis Res 2019;299_ 305.

16. Suhs KW, Hein K, Sattler MB, Gorlitz A, Ciupka C, Scholz $\mathrm{K}$, et al. A randomized, double-blind, phase 2 study of erythropoietin in optic neuritis. Ann Neurol 2012;72:199_ 210.

17. Diem R, Molnar F, Beisse F, Gross N, Drüschler K, Heinrich $\mathrm{SP}$, et al. Treatment of optic neuritis with erythropoietin (TONE): a randomised, double-blind, placebo-controlled trial-study protocol. BMJ Open 2016;6:e010956.

18. Suhs KW, Papanagiotou P, Hein K, Pul R, Scholz K, Heesen $C$, et al. Disease activity and conversion into multiple sclerosis after optic neuritis is treated with erythropoietin. Int J Mol Sci 2016;17:1666. 
This is an open access journal, and articles are distributed under the terms of the Creative Commons Attribution-NonCommercial-ShareAlike 4.0 License, which allows others to remix, tweak, and build upon the work non-commercially, as long as appropriate credit is given and the new creations are licensed under the identical terms.

\section{Access this article online}

Website:

https://knepublishing.com/index.php/JOVR

DOI:

10.18502/jovr.v14i3.4778

How to cite this article: Foroozan R. Erythropoietin for optic neuritis. J Ophthalmic Vis Res 2019;14:240-242. 